
Vercellino, Soledad

Reseña de Teoría y metodología de la extensión universitaria: el caso argentino de Marcelo Luis López.

Cuadernos de Extensión Universitaria de la UNLPam, Año 4, № 4, abril-diciembre 2020. Sección: Reseñas,

\section{DATOS DE PUBLICACIÓN}

Título del libro: Teoría y metodología de la extensión universitaria: el caso argentino.

Autor: Marcelo Luis López

Año de publicación: 2020

Editorial y lugar de edición: El Siku, San Salvador de Jujuy.

ISBN: 978-987-26670-2-3
DATOS DE AUTORA

DE LA RESEÑA

\section{Autora: Soledad Vercellino}

Universidad Nacional de Río Negro, Centro Interdisciplinario de Estudios sobre Derechos, Inclusión y Sociedad.

Dirección electrónica: svercellino@unrn.edu.ar

ORCID: https://orcid.org/0000-0002-1087-5455

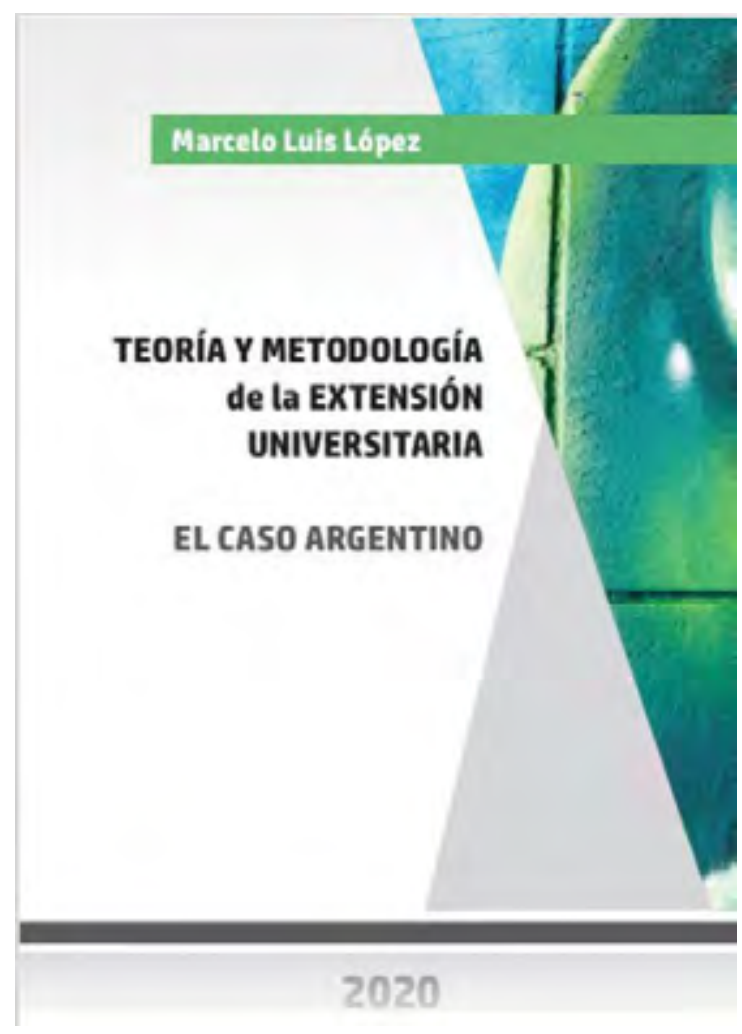


El doctor Marcelo Luis López, docente investigador de la Universidad Nacional de Jujuy, condensa en esta obra su larga trayectoria no solo como extensionista sino, y allí algo de la novedad de este material, como investigador de la extensión universitaria y como formador de grado y posgrado en torno a esta temática. Así, este libro supone una presentación sistemática y enriquecida de publicaciones que desde el 2013 han aparecido en distintas revistas científicas nacionales e internacionales y de hallazgos de su propia tesis doctoral.

"Teoría y metodología de la extensión universitaria: el caso argentino" es, como el mismo autor lo define, "un manual introductorio gratuito, vía internet, pergeñado en tamaño de hoja A4 (el más común en Argentina) para que pueda ser impreso de manera domiciliaria a simple o doble faz" (López, 2020, p. 2). $Y$ en esa instrucción excesivamente pragmática reside el sentido final de la obra: viralizar un estudio riguroso que ubica a la extensión como una tarea consolidada en el campo de la educación superior, fundamentalmente universitaria, con una historia centenaria y sobre la que se va construyendo un campo conceptual y metodológico, no exento de disputas, las que son siempre epistémicas y políticas.

Es un manual, una hoja de ruta, una síntesis de la historia, de las tradiciones conceptuales, de las estrategias metodológicas más usuales desarrolladas en ese campo tan prolífero como, a veces, difuso, que es la extensión universitaria. Pero también es un manifiesto que procura, en la recuperación de tantas experiencias extensionistas desperdiciadas, militar por el valor que tiene el trabajo de los/as actores universitarios en el ámbito socio-comunitario, tanto para la formación de profesionales comprometidos y prudentes como en la promoción de una vida un poco más digna para nuestras comunidades.

El libro se organiza en cinco capítulos. En el capítulo I el autor historiza el desarrollo de la extensión en las universidades del mundo, con especial énfasis en el caso argentino. Distingue sus orígenes en la tradición inglesa y el posterior surgimiento de las universidades populares. En el caso argentino propone, adaptando periodizaciones de Fernández Lamarra (2002) y Bona (2017), diez etapas en el devenir extensionista desde la universidad oligárquica y liberal (1885 1917) hasta la extensión universitaria en el período de la Posconvertibilidad (2002 - 2015). Este ejercicio 
genealógico permite entender cómo, aún con cierta revitalización que se ha dado a la extensión a partir del 2003, persiste "un tinte de la extensión universitaria marcadamente asistencialista -que continúa con la tradición pragmática de poca investigación al respecto- con las posiciones vinculacionistas" (López, 2020, p.23) provenientes de la década del 90.

El capítulo 2 presenta los principales enfoques y lógicas de la extensión universitaria. ¿Qué sentidos hegemónicos han primado a la hora de definir los alcances, modalidad, dirección y valores que deben orientar la relación universidad y sociedad? De manera fundamentada, pero a la vez didáctica, el autor argumentará dos significantes y significados fuertes asociados a esa vinculación: el de extensión universitaria y el de vinculación tecnológica.

A su vez, analizará cómo la noción de extensión universitaria engloba una serie de sentidos que podríamos ubicar en un polo, más tradicional, originario, de tipo asistencialista, y otro, crítico de este, que denomina extensionismo crítico-emancipatorio. "El extensionismo asistencialista deviene de la extensión obrerista, cursista y clasista inglesa", señala López (2020, p. 30). Sus presupuestos son la divulgación de la ciencia y la cultura desde una posición en que lo que lo que el otro necesita es impuesta por el sujeto universitario, quien define contenidos, objetivos, estrategias, etc. El extensionismo crítico- emancipatorio, considera a la extensión universitaria como una herramienta para la superación de la desigualdad. En esta concepción la demanda surge de la interacción social entre el sujeto extensionista y el sujeto destinatario, la definición de objetivos, contenidos, estrategias es conjunta, colaborativa.

En el capítulo 3 analiza críticamente otras categorías subsidiarias, articulables y articuladas -y no poca veces asumidas homólogamente- a la extensión, como las de responsabilidad social universitaria, emprendedurismo y desarrollo local vinculados a los procesos que impactan en los polos capital y trabajo.

En el capítulo 4, a partir de una sólida revisión y análisis crítico sobre la literatura sobre extensión publicada en Latinoamérica y de las comunicaciones presentadas en los cuatro Congresos Nacionales de Extensión Universitaria de Argentina, López realiza una cartografía de lo que denomina la "teoría extensionista" y puntea las principales prácticas 
metodológicas utilizadas. Allí se desandan nociones como las de aprendizaje en servicio, las metodologías participativas (investigación acción participativa y otras asociadas), el dispositivo del taller y el problema de la demanda.

En el último capítulo vuelve a la producción condensada en los Congresos Nacionales de Extensión Universitaria para delinear los contornos de ese amplio campo de problemas que es la extensión. Identifica homogeneidades y heterogeneidades en relación con las condiciones causales e intervinientes que llevaron a la realización de esos eventos, las estrategias de acción que los impulsaron y las consecuencias de sus aportes acerca de la construcción del objeto extensión universitaria. Sobre este último punto, aborda cuáles son las principales temáticas en torno a las cuales se desarrollan las prácticas extensionistas y la reflexión sobre esta (salud, educación, la propia extensión como objeto de reflexión, la producción primaria, el campo del derecho, la comunicación, la economía, etc.). También repara, entre otras cuestiones, en cuáles son los objetos y quiénes los sujetos transversalizados abordados u omitidos en esos eventos: ubica a los contextos de privación de la libertad (internos, liberados, instituciones), la integración de funciones (docencia-investigación-extensión), la problemática medioambiental y los procesos de curricularización y formación en extensión universitaria como tópicos fuertemente abordados.

"Teoría y metodología de la extensión universitaria: el caso argentino" es un libro necesario. En él encontramos la marca de un académico comprometido con la extensión, pero también consciente, como buen pedagogo que es, en que estas demandas que se hacen a las instituciones de educación superior (no por nuevas, sino por ir a contramano de la gramática universitaria, de sus formas duras) deben estar acompañadas de la producción de teorías y metodologías, de una pedagogía, que enmarque, oriente, los procesos formativos.

Lo definiría como un libro de Pedagogía de la Extensión, sólidamente fundamentado en la recuperación de la rica y variada experiencia extensionista de nuestras universidades. Es un libro que servirá para dar un marco referencial a quienes insistimos, a partir de cierto empecinamiento ético político en desarrollar tareas extensionistas como estrategia de formación y vinculación con la sociedad. 


\section{Bibliografía}

Bona, M. L. (2017). Costo de reproducción social en Argentina. Evolución durante los períodos de convertibilidad (1991-2001) y posconvertibilidad (2002-2015). Sociedad y economía, No. 34, 145166. Recuperado de http://revistaprospectiva. univalle.edu.co/index.php/sociedad_y_economia/ article/view/6476

Fernández Lamarra, N. (2002). La educación Superior en la Argentina. Buenos Aires: IESALC/UNESCO. 
